\title{
Absorption Spectra of the $4 \mathrm{f}$ Electron Transitions of the Praseodymium Complex with 1-Cyclopropyl-6-fluoro-1,4- dihydro-7-(4-ethyl-1-piperazinyl)-4-oxo-3-quinoline Carboxylic Acid Hydrochloride and Its Analytical Application
}

\author{
Naixing WAng, ${ }^{* \dagger}$ Wei JIAng, ${ }^{*}$ Zhikun SI,* Fuxiang LIU,* Quanjie Men, ** and Xiuqin XU*** \\ *Department of Chemistry, Shandong University, Jinan, 250100, People's Republic of China \\ **Shandong Provincial City Building School, Jinan, People's Republic of China \\ ***Hospital of Shandong University, Jinan, 250100, People's Republic of China
}

\begin{abstract}
The absorption spectra of the praseodymium complex with 1-cyclopropyl-6-fluoro-1,4-dihydro-7-(4-ethyl-1-piperazinyl)4-oxo-3-quinoline carboxylic acid hydrochloride (NNFX) has been studied by normal and derivative spectrophotometry. The complex showed maximum absorption at $350 \mathrm{~nm}$ at $\mathrm{pH}$ 6.0. The stoichiometry of the Pr-NNFX complex was calculated by the molar ratio and continuous variation methods. The ratio of Pr to NNFX was 1:3. The absorption bands of the $4 \mathrm{f}$ electron transitions of the praseodymium complex with NNFX are enhanced markedly, especially the wavelength at $481 \mathrm{~nm}$. Using the third-derivative spectrum, the calibration graph is linear over the range $2.5 \times 10^{-5}-3.5$ $\times 10^{-4} \mathrm{~mol} \mathrm{dm}^{-3}$ for praseodymium. The detection limits (signal-to-noise ratio of 2) is $1.4 \times 10^{-6} \mathrm{~mol} \mathrm{dm}^{-3}$. The relative standard deviation is $1.2 \%$ for $7.0 \times 10^{-5} \mathrm{~mol} \mathrm{dm}^{-3}$ of praseodymium. A method for the direct determination of praseodymium in rare earth mixtures with good accuracy and selectivity is described.
\end{abstract}

(Received February 27, 2001; Accepted June 21, 2001)

A number of metallochromic reagents have been described for the spectrophotometric determination of praseodymium. ${ }^{1-5}$ None of them are specific for praseodymium in the presence of other rare earths because of a considerable overlap between their broad absorption spectra. However, there has long been interest in the determination of individual elements based on the absorption bands of their $4 \mathrm{f}$ electron transitions. ${ }^{6-11}$ In recent papers, the third/second derivative spectrophotometric determination of complexes formed by some rare earths with 8 hydroxylquinoline and its derivative, ${ }^{12-15} \beta$-diketones ${ }^{16,17}$ and inorganic salts ${ }^{18,19}$ were investigated, which can be utilized for the determination of neodymium, holmium and erbium. However, applications to praseodymium are rare.

1-Cyclopropyl-6-fluoro-1,4-dihydro-7-(4-ethyl-1piperazinyl)-4-oxo-3-quinoline carboxylic acid hydrochloride (NNFX) is the third representative of antibacterial medicine, namely the quinolone group, used extensively in clinical treatment with higher potential and a broad antibacterial spectrum as well as fewer side effect. However, its utilization as a reagent for the determination of rare earth elements has not been reported. In the present work, the absorption spectra of the praseodymium complex with NNFX was investigated by applying both normal and derivative spectrophotometric methods. On this basis, a method was developed for the direct determination of praseodymium in rare earth mixtures. The analytical results obtained are satisfactory.

\section{Experimental}

\section{Apparatus}

A Shimadzu UV-3000 double-beam spectrophotometer
(Kyoto, Japan) with 4.0-cm cells was used. The pH-values of the solutions were measured with a pHs-2 meter (Analytical Apparatus Plant, Shanghai, China).

\section{Reagents and chemicals}

Stock lanthanide solutions $(0.01 \mathrm{M})$ were prepared by dissolving an appropriate amount of pure oxides (Johnson Matthey, Royston, Hertfordshire, UK) in hydrochloric acid $(1+1)$, and working solutions were prepared by dilution with water. A solution of 1-cyclopropyl-6-fluoro-1,4-dihydro-7-(4ethyl-1-piperazinyl)-4-oxo-3-quinoline carboxylic acid hydrochloride (NNFX, $0.05 \mathrm{M}$ ) was prepared by dissolving $1.797 \mathrm{~g}$ of NNFX (Zibo Pharmacy Plant, People's Republic of China) in $100 \mathrm{ml}$ of distilled water in a calibrated flask. A buffer solution of $\mathrm{pH} 6.0$ was prepared by dissolving $200 \mathrm{~g}$ of hexamethylene tetramine in $500 \mathrm{ml}$ of distilled water, the $\mathrm{pH}$ being adjusted with hydrochloric acid $(1+1)$ and diluting to $1000 \mathrm{ml}$ with distilled water.

Analytical-reagent grade chemicals were used whenever possible.

\section{Procedure}

A known volume of a lanthanide solution (containing Pr up to $50 \mu \mathrm{g}$ ) was transferred into a $10 \mathrm{ml}$ calibrated flask; $3.0 \mathrm{ml}$ of $0.05 \mathrm{M}$ NNFX and $4.0 \mathrm{ml}$ of $\mathrm{pH} 6.0$ buffer solutions were added. The mixture was diluted to the mark with distilled water, and after $30 \mathrm{~min}$ the third-derivative spectra were recorded against a reagent blank using $4.0-\mathrm{cm}$ cells with a $\Delta \lambda$ of $2.8 \mathrm{~nm}$, a band pass of $1.0 \mathrm{~nm}$ and a scan rate $=50 \mathrm{~nm} \mathrm{~min}^{-1}$ as instrumental parameters. The amplitudes were measured between the $484.5(+) \mathrm{nm}$ positive peak and the $482.5(-) \mathrm{nm}$ negative peak for praseodymium.

\footnotetext{
$\doteqdot$ To whom correspondence should be addressed.
} 


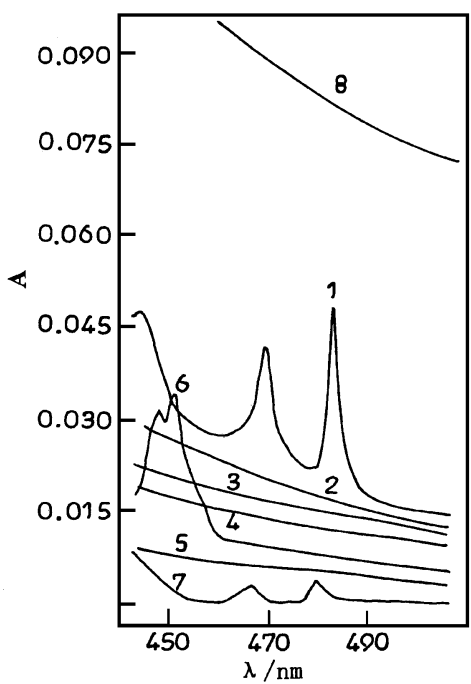

Fig. 1 Absorption spectra of the reagent, lanthanide complexes, and praseodymium ion. $\left[\mathrm{Ln}^{3+}\right]=2.5 \times 10^{-4} \mathrm{M},[\mathrm{NNFX}]=1.5 \times 10^{-2}$ M. $\mathrm{pH}=6.0,4.0$-cm cells. 1, Pr; 2, La; 3, Nd; 4, Gd; 5, Er; 6, Ho; 7, $\mathrm{Pr}^{3+}\left(\mathrm{PrCl}_{3}\right) ; 8$, NNFX. Reference: $1-6$, reagent blank; $7 \& 8$, water.

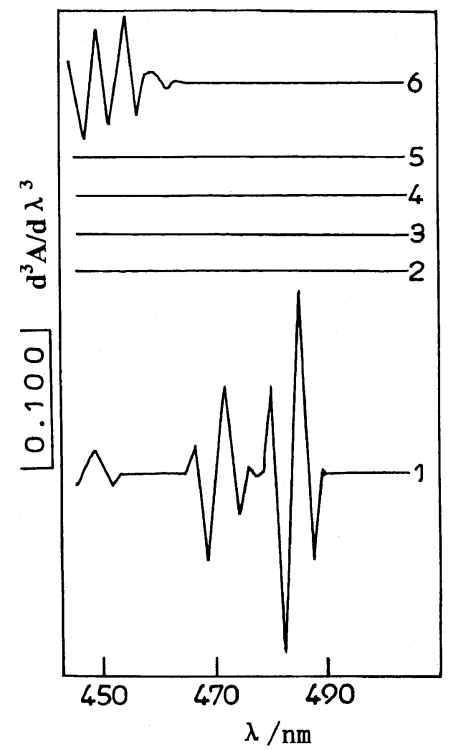

Fig. 2 Third-derivative spectra of lanthanide complexes. $\Delta \lambda=2.8$ $\mathrm{nm}$, band pass $=1.0 \mathrm{~nm}$, scan rate $=50 \mathrm{~nm} \mathrm{~min}{ }^{-1}$. Other conditions were the same as in Fig. 1, curves $1-6$.

\section{Results and Discussion}

\section{Absorption spectra}

The absorption spectra of $\mathrm{Pr}^{3+}, \mathrm{Ln}^{3+}-\mathrm{NNFX}$ and NNFX systems are shown in Fig. 1. From Fig. 1, it is evident that the differences between curves 1 and 7 show some changes in the spectral features. The absorption peaks of $\mathrm{Pr}^{3+}$ as chloride are at $466.5 \mathrm{~nm}$ and $480 \mathrm{~nm}$; those of the complex move to longer wavelengths of $469 \mathrm{~nm}$ and $483 \mathrm{~nm}$. The sensitivity is enhanced by factors of 6.5 (at $469 \mathrm{~nm}$ ) and 8.3 (at $483 \mathrm{~nm}$ ), respectively. It can be concluded that the absorption bands are changed because the strength of the coordinate field of NNFX surrounding the $\mathrm{Pr}^{3+}$ is sufficient to penetrate the shielding by $5 \mathrm{~s} 5 \mathrm{p}$ shells. A narrow absorption band at $483 \mathrm{~nm}$

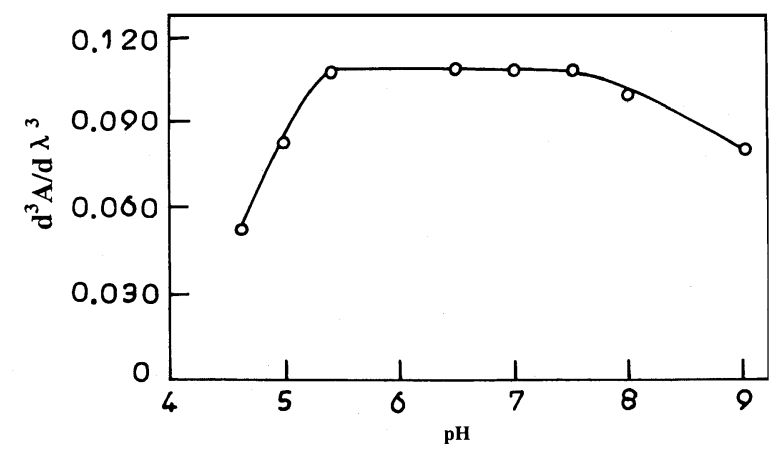

Fig. 3 Effect of the $\mathrm{pH}$ on the absorbance of the complex. $\left[\mathrm{Pr}^{3+}\right]=$ $1.0 \times 10^{-4} \mathrm{M},[\mathrm{NNFX}]=1.5 \times 10^{-2} \mathrm{M}$. The instrumental parameters were the same as in Fig. 2. The Pr peak-to-valley amplitude measurements were at $484.5(+) \mathrm{nm}$ and $482.5(-) \mathrm{nm}$.

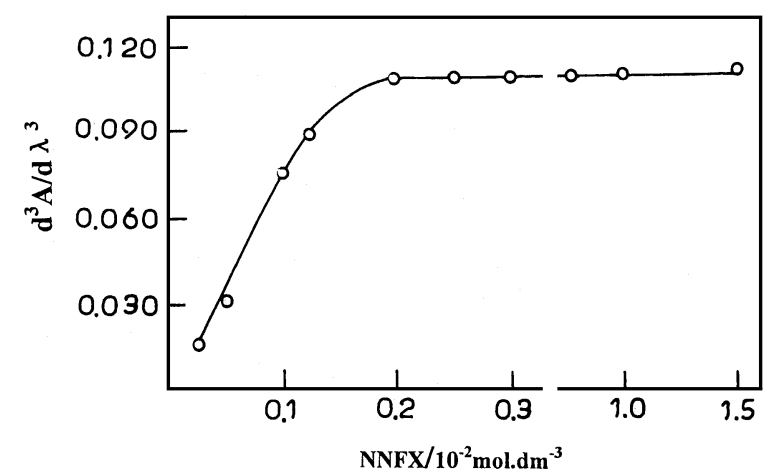

Fig. 4 Effect of NNFX on the absorbance of the complex. $\mathrm{pH}=$ 6.0. Other conditions were the same as in Fig. 3, except for the NNFX concentrations.

corresponding to the ${ }^{3} \mathrm{H}_{4} \rightarrow{ }^{3} \mathrm{P}_{0}$ transition ${ }^{20}$ of $\mathrm{Pr}^{3+}$, allows its determination by means of the derivative spectra. The other lanthanide complexes in this wavelength range show only pure complex background absorption, except that the 4f electron transitions of the holmium complex at $450 \mathrm{~nm}$ was lightly enhanced. The experimental results show that the normal spectrophotometry for praseodymium is subject to interference of the pure complexes background absorption by other lanthanides. Therefore, we investigated the first- to fourthderivative spectra of different lanthanide complexes and variable measuring parameters of the instrument. The optimum instrumental conditions for praseodymium determination are the use of the third-derivative spectrum with a $\Delta \lambda$ of $2.8 \mathrm{~nm}$, a band pass of $1.0 \mathrm{~nm}$ and a scan rate of $50 \mathrm{~nm} \mathrm{~min}{ }^{-1}$, because they afforded the best sensitivity. Figure 2 shows the thirdderivative spectra of the representative lanthanide complexes. It is obvious that the optimal analytical signals are at $484.5(+) \mathrm{nm}$ positive peak and 482.5(-) nm negative peak for the praseodymium complex, where other lanthanide complexes produce only a constant absorption signal, thus causing no interference for praseodymium.

\section{Optimization of reaction conditions}

The chemical variable $\mathrm{pH}$ and reagent were optimized for praseodymium by varying one of them at a time (see Figs. 3 and 4). On this basis, the optimum conditions for praseodymium thus selected were those given in the procedure. Taking into account the consumption of the reagent by other lanthanides in the mixtures, the NNFX amount recommended in the procedure 


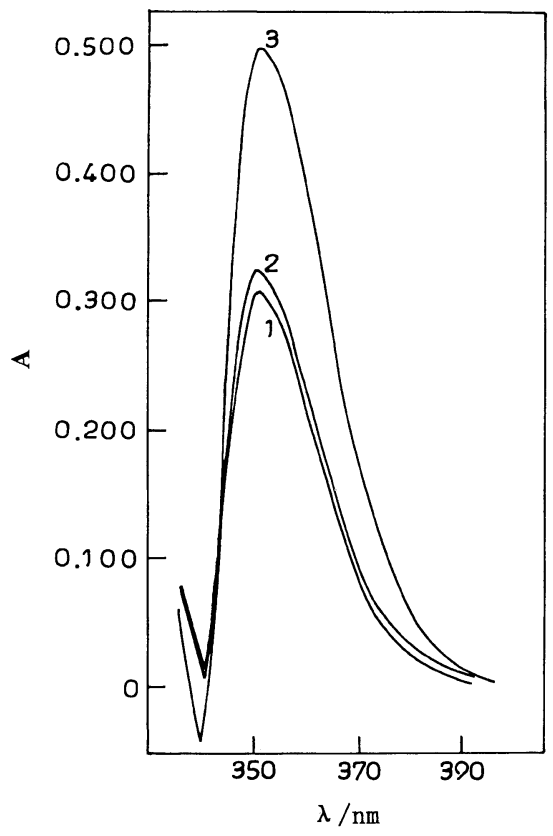

Fig. 5 Absorption spectra of the different complexes. $\left[\mathrm{Pr}^{3+}\right]=$ $\left[\mathrm{Nd}^{3+}\right]=\left[\mathrm{Ho}^{3+}\right]=1.0 \times 10^{-4} \mathrm{M},[\mathrm{NNFX}]=3.0 \times 10^{-4} \mathrm{M} . \mathrm{pH}=6.0$, 1.0-cm cells. $1, \operatorname{Pr} ; 2, \mathrm{Nd} ; 3$, Ho

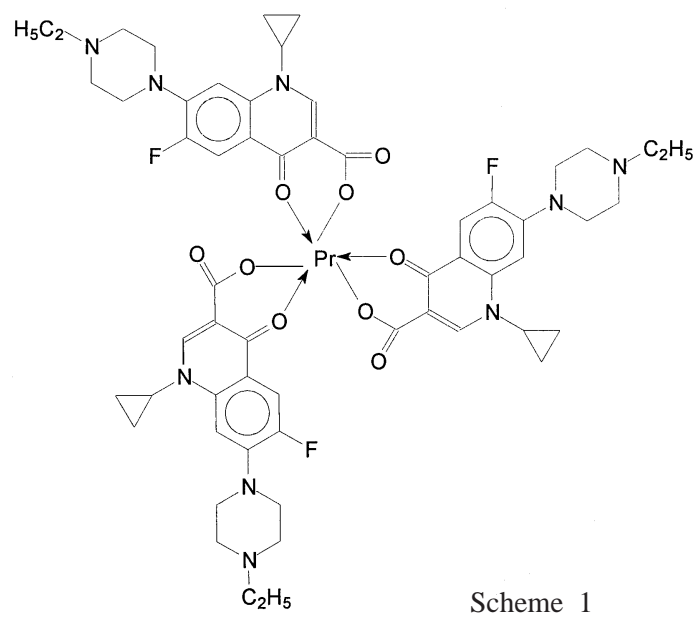

is about 20-times greater than necessary for the sum of the lanthanides present. The complex takes $25 \mathrm{~min}$ to form, and the derivative absorption signal is stable for at least $48 \mathrm{~h}$.

\section{Determination of the stoichiometry of the complex}

The determination of the composition of the complex by means of the visible absorption spectra based on the $4 \mathrm{f}$ electron transitions of the praseodymium complex are not definitive conclusions because the absorption signals vary little with the changes in the NNFX concentration. Therefore, the ultraviolet absorption spectra of the complexes of the praseodymium and other lanthanides at $\mathrm{pH} 6.0$ were studied. Figure 5 shows the absorption spectra of some lanthanide complexes, from which it was found that the complexes have a maximum absorption peak at $350 \mathrm{~nm}$, and that the spectral characteristics of the complexes are similar.

With praseodymium as a representative, the composition of the complex was investigated by means of the molar ratio and continuous-variation methods. The experimental results are shown in Fig. 6. Both methods produced similar results,
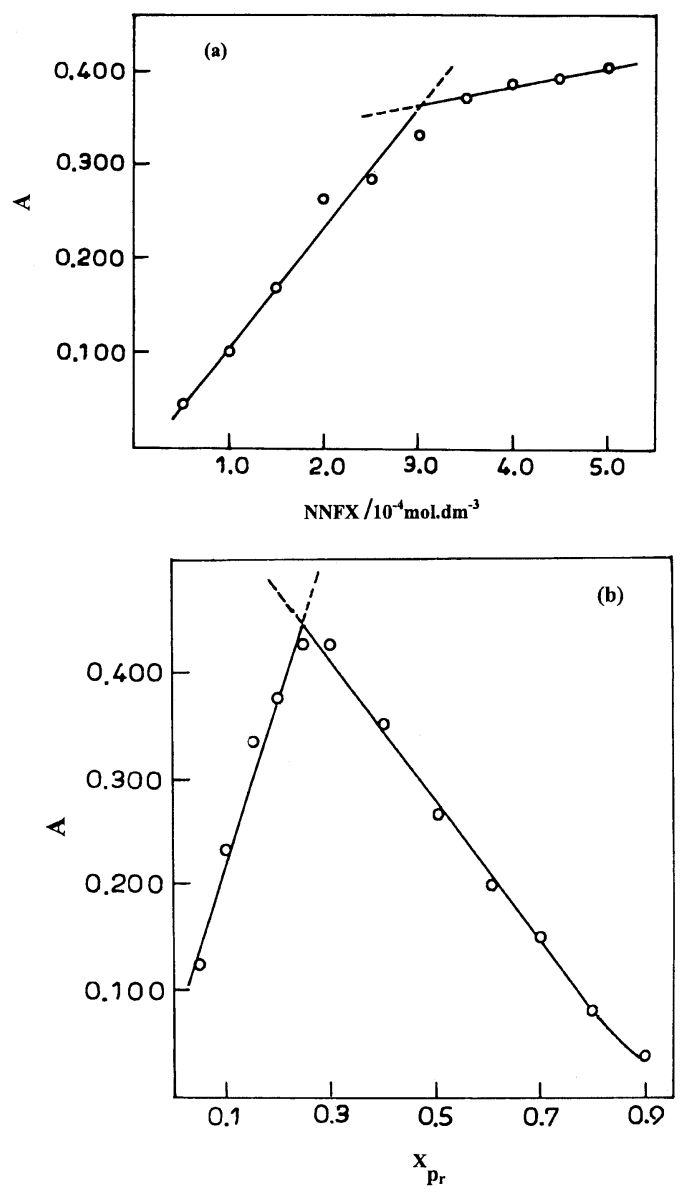

Fig. 6 Determination of the stoichiometry of the complex. $\mathrm{pH}=$ $6.0,1.0-\mathrm{cm}$ cells, $\lambda=350 \mathrm{~nm}$. (a) Molar ratio method, $\left[\mathrm{Pr}^{3+}\right]=1.0 \times$ $10^{-4} \mathrm{M}$. (b) Continuous variation method for the Pr to NNFX ratio; total concentration $=5.0 \times 10^{-4} \mathrm{M}$.

showing that the complex had a praseodymium-to-ligand ratio of $1: 3$. We therefore guess that the complex $\operatorname{Pr}(\mathrm{NNFX})_{3}$ is formed under the experimental conditions, the structure of which is probably as shown in Scheme 1. The results for the other elements $(\mathrm{Nd}, \mathrm{Ho}$, etc.) are similar to those of $\mathrm{Pr}$.

Calibration graphs, precision and detection limits

The third derivative spectra (Fig. 7) provide a linear calibration graph over the range $2.5 \times 10^{-5}-3.5 \times 10^{-4} \mathrm{M}$ of praseodymium (in the final solution). The equation obtained by the least-squares method is

$$
\mathrm{d} A=0.0012+7.41\left[\operatorname{Pr}^{3+}\right], r=0.9993(n=8),
$$

where $\left[\mathrm{Pr}^{3+}\right]$ is the concentration in $\mathrm{M}$, and $r$ is the correlation coefficient. The relative standard deviation evaluated from seven independent determinations of $7.0 \times 10^{-5} \mathrm{M}$ of praseodymium are $1.2 \%$ for praseodymium alone and $1.49 \%$ in the presence of $7.0 \times 10^{-4} \mathrm{M}$ lanthanum. The detection limit (signal-to-noise ratio $=2$ ) is $1.4 \times 10^{-6} \mathrm{M}$.

\section{Effect of diverse ions}

The effect of foreign ions and REEs ions was studied by adding a solution of the ions to a sample containing $7.0 \times 10^{-5}$ $\mathrm{M}$ of praseodymium and subjecting the solution to the above procedure. The highest permissible molar excesses of other ions (i.e., causing a $\pm 5 \%$ relative error in the third-derivative absorption signals) were as follows: $\mathrm{Mg}^{2+}(800)$; $\mathrm{Ca}^{2+}(650)$; $\mathrm{Sr}^{2+}$, 


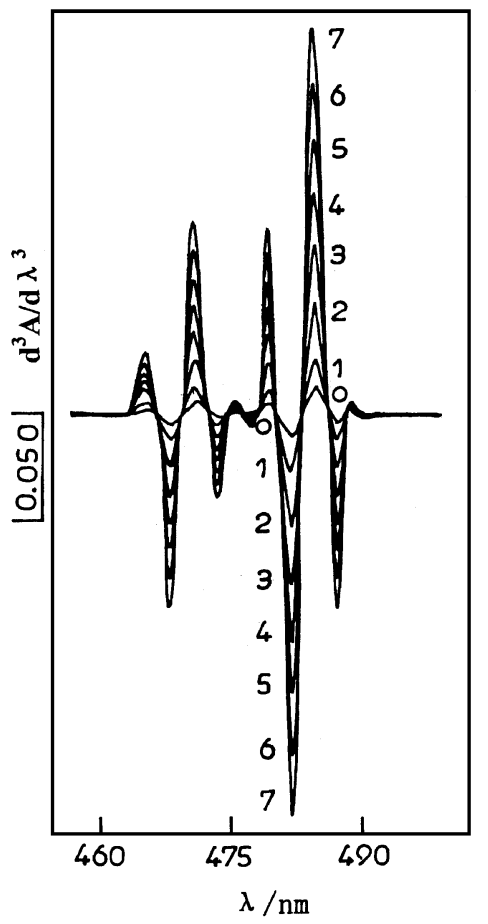

Fig. 7 Spectral curves for the praseodymium complex. $[\mathrm{NNFX}]=$ $1.5 \times 10^{-2} \mathrm{M}, \mathrm{pH}=6.0$. The instrumental parameters were the same as in Fig. 2. Curves from inner to outer, $\left([\mathrm{Pr}] \times 10^{-4} \mathrm{M}\right): 0,0.25 ; 1$, $0.50 ; 2,1.00 ; 3,1.50 ; 4,2.00 ; 5,2.50 ; 6,3.00 ; 7,3.50$.

Table 1 Compositions of synthetic samples (oxides $\% \mathrm{~m} / \mathrm{m}$ ) and analytical results

\begin{tabular}{|c|c|c|}
\hline Present & $\begin{array}{l}\text { Found }^{\mathrm{a}} \\
\quad \%\end{array}$ & $\begin{array}{c}\mathrm{RSD}^{\mathrm{b}}, \\
\%\end{array}$ \\
\hline $\begin{array}{l}\text { No. } 1 \text { La 21.04, Ce(IV) 47.52, Pr 3.70, Nd 14.60, Ho } 4.00 \\
\text { Sm 0.80, Eu 0.73, Gd 1.21, Tb 0.20, Er 4.00 }\end{array}$ & 03.55 & 2.0 \\
\hline $\begin{array}{l}\text { No. } 2 \text { La } 1.85, \mathrm{Ce}(\mathrm{IV}) 3.62, \operatorname{Pr} 5.50, \mathrm{Nd} 3.25, \mathrm{Sm} 1.89, \\
\quad \mathrm{Eu} 1.13, \mathrm{Gd} 10.27, \mathrm{~Tb} 5.78, \mathrm{Ho} 4.22, \mathrm{Er} 6.00, \mathrm{Y} 56.49\end{array}$ & 5.62 & 1.7 \\
\hline
\end{tabular}

a. Average of five determinations.

b. $\mathrm{RSD}=$ relative standard deviation $(n=5)$

$\mathrm{Ni}^{2+}, \mathrm{Co}^{2+}(280) ; \mathrm{Cu}^{2+}, \mathrm{Cr}^{3+}, \mathrm{Zn}^{2+}(250) ; \mathrm{Ga}^{3+}, \mathrm{In}^{3+}, \mathrm{Mn}^{2+}(120)$; $\mathrm{Ln}^{3+}(100) ; \mathrm{Hg}^{2+}, \mathrm{Au}^{3+}, \mathrm{Ti}^{4+}, \mathrm{Th}^{4+}, \mathrm{Zr}^{4+}, \mathrm{Pb}^{2+}, \mathrm{Ce}^{3+}, \mathrm{Ce}^{4+}(80)$; $\mathrm{Fe}^{3+}(20)$. Larger amounts decreased the absorption signals.

\section{Analytical application}

In order to evaluate the applicability of the proposed method, the results obtained for two synthetic samples (prepared based on the relative contents of rare earth oxides in the earth's crust $^{21}$ ) are given in Table 1.

In addition, two reference materials and a lanthanide base rock sample containing a little $\mathrm{Ca}, \mathrm{Mg}, \mathrm{Sr}, \mathrm{Fe}, \mathrm{AI}, \mathrm{Th}, \mathrm{Zr}$ metals were also analyzed for praseodymium. In the procedure, $0.5 \mathrm{~g}$ of the reference material was dissolved in $10 \mathrm{ml}$ of hydrochloric acid $(1+1)$ by heating with a few drops of hydrogen peroxide, and then evaporated nearly to dryness on a water-bath. The residue was dissolved in water, filtered if needed and diluted to $100 \mathrm{ml}$ with water in a calibrated flask. An aliquot $(0.50-1.50$ $\mathrm{ml}$ ) of this solution was diluted and transferred into a $10 \mathrm{ml}$ calibration flask. The praseodymium content was then determined by the above procedure. The obtained results are given in Table 2. These results are in agreement with the
Table 2 Analytical results of praseodymium in three reference materials

\begin{tabular}{lllc}
\hline \multicolumn{1}{c}{ Present (oxides \%m/m) } & Found $^{\mathrm{a}}$ & $\mathrm{RSD}^{\mathrm{b}}$ \\
\hline No.1 & La 27.11, Ce(IV) 49.21, Pr 5.18, Nd 16.75, Dy 0.09 & 5.15 & \multirow{2}{*}{1.2} \\
& Eu 0.23, Sm 1.29, Gd 0.40, Tb 0.03, Tm 0.0095 & & \\
& Ho 0.023, Er 0.027, Y 0.27, Yb 0.013, Lu 0.003 & & \\
No.2 & La 13.83, Ce(IV) 62.98, Pr 5.76, Nd 14.43, Eu 0.25 & 5.60 & 1.0 \\
& Yb 0.015, Gd 0.42, Tb 0.027, Dy 0.077, Ho 0.019 & & \\
& Er 0.022, Y 0.045, Tm 0.0076, Sm 1.83, Lu 0.001 & & \\
No.3 & La 23.10, Ce(IV) 0.90, Pr 7.31, Nd 21.53, Sm 2.21, & 7.21 & 0.88 \\
& Tb 0.32, Y 5.25, Ho 0.98, Er 0.30, Yb 0.24, Gd 3.24 & & \\
\hline
\end{tabular}

a. Average of five determinations.

b. $\mathrm{RSD}=$ relative standard deviation $(n=5)$.

No.1 and No.2 form Baotou Rare Earths Academy, China.

No.3 from Jiangxi Xiunwu lanthanide base rock samples, China

certified values.

\section{Acknowledgements}

This work was financially supported by the Natural Science Foundation of Shandong Province.

\section{References}

1. N. M. Kailash and A. K. Dey, Chem. Anal., 1969, 53, 105.

2. V. Chandrasekhar and N. M. Kailash, Indian J. Chem., 1976, 14, 189.

3. I. G. Surin, Zh. Anal. Khim., 1979, 34, 1103.

4. R. Sukumar, P. T. Rao, and A. D. Damodaran, Analyst, 1988, 113, 1061 .

5. J. Mendez Hernandez, B. Cordero Moreno, and J. L. Pavon Perez, Talanta, 1988, 4, 293.

6. T. Taketatsu and C. V. Banks, Anal. Chem., 1966, 38, 1524.

7. L. I. Kononenko, M. A. Tishchenko, and V. N. Drobyazko, Zh. Anal. Khim., 1971, 26, 729.

8. J. Z. Gao, J. W. Kang, and G. B. Bei, Kexue Tongbo, 1979, $24,1119$.

9. T. Taketatsu and N. Toriumi, Talanta, 1970, 17, 465.

10. J. W. Kang, R. Y. Chen, and G. B. Bei, Acta Chim. Sin., 1984, 42, 921.

11. Y. Ren and P. X. Zhang, Acta Chim. Sin., 1986, 44, 920.

12. N. X. Wang, W. A. Liang, and Z. Z. Zhang, Analyst, 1992, 117, 1963.

13. N. X. Wang, Q. C. Wu, J. B. Shi, and P. Qi, Mikrochim. Acta, 1993, 110, 119.

14. N. X. Wang and P. Qi, Anal. Lett., 1992, 6, 1119.

15. N. X. Wang, Z. K. Si, W. Jiang, and Z. C. Qi, Analyst, 1996, 1211317.

16. N. X. Wang, Z. K. Si, and W. Jiang, Spectrochim. Acta, 1997, 53, 829 .

17. J. H. Yang, N. X. Wang, Y. J. Wang, W. A. Liang, H. M. Ge, and J. Zhou, Spectrochim. Acta, 1995, 51, 185.

18. H. Ishii and K. Satoh, Bunseki Kagaku, 1986, 8, 704.

19. P. K. Spitsin and O. N. Lvov, Zh. Anal. Khim., 1985, 7, 1241.

20. D. E. Henrie, R. L. Fellows, and G. R. Choppin, Coord. Chem. Revs., 1976, 18, 199.

21. Y. E. Zeng, J. K. Cheng, and Q. Y. Luo, "Analytical Chemistry of Rare Earth Elements", 1981, Science Press, Beijing, Part 1, 6. 